\title{
Mid-term functional outcome after the internal fixation of distal radius fractures
}

\author{
Joideep Phadnis ${ }^{1 *}$, Alex Trompeter ${ }^{2}$, Kieran Gallagher ${ }^{3}$, Lucy Bradshaw ${ }^{4}$, David S Elliott ${ }^{3}$ and Kevin J Newman ${ }^{3}$
}

\begin{abstract}
Background: Distal radius fracture is a common injury with a variety of operative and non-operative management options. There remains debate as to the optimal treatment for a given patient and fracture. Despite the popularity of volar locking plate fixation, there are few large cohort or long term follow up studies to justify this modality. Our aim was to report the functional outcome of a large number of patients at a significant follow up time after fixation of their distal radius with a volar locking plate.

Methods: 180 patients with 183 fractures and a mean age of 62.4 years were followed up retrospectively at a mean of 30 months (Standard deviation $=10.4$ ). Functional assessment was performed using the Disabilities of the Arm, Shoulder and Hand (DASH) and modified MAYO wrist scores. Statistical analysis was performed to identify possible variables affecting outcome and radiographs were assessed to determine time to fracture union.

Results: The median DASH score was 2.3 and median MAYO score was 90 for the whole group. Overall, 133 patients (74\%) had a good or excellent DASH and MAYO score. Statistical analysis showed that no specific variable including gender, age, fracture type, post-operative immobilisation or surgeon grade significantly affected outcome. Complications occurred in 27 patients (15\%) and in 11 patients were major (6\%).

Conclusion: This single centre large population series demonstrates good to excellent results in the majority of patients after volar locking plate fixation of the distal radius, with complication rates comparable to other nonoperative and operative treatment modalities. On this basis we recommend this mode of fixation for distal radius fractures requiting operative intervention.
\end{abstract}

Keywords: Distal Radius, Fracture, Internal fixation: functional outcome

\section{Background}

Fractures of the distal radius are common [1-3]. Increasing incidence of these injuries may be attributed to an ageing population (osteoporotic fractures) and the growing participation in outdoor pursuits (higher energy fractures) $[4,5]$. Various operative and non-operative modalities are available for treatment, but there remains controversy as to the optimal method for a given patient and fracture type [2,3]. Volar locking plate fixation has become increasingly popular, especially in patients with osteoporotic bone and this is reflected by the number of implants available on the market [6]. Despite this there are few long term, comparative or large cohort studies

\footnotetext{
* Correspondence: joideep@doctors.org.uk

'Orthopaedic Department, Frimley Park Hospital, Camberley, GU16 7UJ, UK
} Full list of author information is available at the end of the article looking specifically at the functional outcome after volar locking plate fixation.

The aim of this study was to review a large group of patients treated with volar locking plate fixation of their distal radius fracture and to assess their functional outcome at a significant follow up time. Secondary aims were to establish if any individual factors affected this outcome and compare our results with those of other studies.

Our hypothesis was that functional outcome and complication rate after internal fixation of the distal radius with a volar locking plate would be comparable to, or better than other reported treatment modalities.

\section{Methods}

We conducted a retrospective study of patients with fractures of the distal radius managed by internal

\section{Biomed Central}


fixation using the Stryker Matrix Volar Locking Plate (Stryker Leibinger GmbH \& Co. Germany) between June 2004 and October 2007 treated in a single centre. Indications for surgery were displaced intra-articular fractures with post reduction articular step of $>2 \mathrm{~mm}$; radial shortening of $>3 \mathrm{~mm}$ or $>15$ degrees of saggital plane angulation (as measured from the anatomical volar tilted position)[2]. Additionally, fractures with features indicative of instability or poor outcome such as metaphyseal comminution and unsatisfactory radio-carpal alignment were treated surgically [7]. Finally, patients who originally underwent non-operative treatment in plaster but whose fracture displayed one of the above stated parameters for surgery at follow up, and underwent subsequent volar plate fixation were included. Exclusion criteria were fractures treated with alternative instrumentation, fractures over 4 weeks old at the time of surgery, and non-trauma operations such as corrective osteotomies.

\section{Patients}

Using the departmental trauma database, 221 suitable patients were identified for inclusion in the study. One patient was unwilling to participate; six were deceased; 26 were not contactable and eight were unable to participate for medical reasons. The remaining 180 patients with a total of 183 fractures were followed up by means of case note and operative record analysis, radiographic assessment and functional questionnaire.

\section{Outcome assessment}

Case notes were used to establish all demographic details including; mechanism of injury; time to surgery; post-operative immobilisation; surgeon grade and intraoperative details. Complications were also recorded and confirmed with the patients.

The functional questionnaire was telephone based, and utilised the 'quick' Disabilities of Arm, Shoulder and Hand (Quick DASH) score [8-11], and the modified MAYO wrist score [12]. The Quick DASH has been shown to be interchangeable with the traditional DASH score and is simpler to perform $[8,10,11]$. Both MAYO and DASH are scored from $0-100$ but in the DASH score, a score of 100 constitutes the worst outcome whereas in the MAYO score this is equivalent to the best outcome. There are no defined parameters of what constitutes an excellent, good, satisfactory or poor score in the DASH system merely that a score of zero indicates no disability and a score of 100 indicates complete disability. We hence set these parameters ourselves for descriptive purposes. Such parameters are pre-defined in the MAYO score (table 1). JP and KG who were blinded to the patient's demographic details performed the functional assessment for all patients.
Table 1 Outcome grading for Quick DASH and MAYO wrist scores

\begin{tabular}{lll}
\hline & DASH & MAYO \\
\hline EXCELLENT & $0-5$ & $90-100$ \\
\hline GOOD & $6-15$ & $80-90$ \\
\hline SATISFACTORY & $15-35$ & $60-80$ \\
\hline POOR & $>35$ & $<60$ \\
\hline
\end{tabular}

Pre-operative radiographs were classified according to the AO-ASIF classification system [13] and post- operatively were assessed for fracture union. Fracture union was determined by the presence of bridging trabeculae on the AP and Lateral view radiographs or by complete obliteration of the fracture line [14]. These findings were correlated with the case notes to determine whether there was pain on physiologic loading or on palpation before fracture union was declared.

\section{Statistical methods}

Categorical variables and baseline demographic data are described using frequencies and percentages. Continuous variables with a symmetric distribution are presented using means and standard deviations (SD) and continuous variables with a skewed distribution are presented using the median and inter-quartile range (IQR). Demographic variables such as age and gender and operation related variables such as surgeon grade, fracture type and time to surgery were considered to establish if any of these factors affected functional outcome. Spearman's rank correlation coefficient was used to assess the association between continuous variables and non-parametric tests (Mann-Whitney and KruskalWallis) were used to test for differences in outcome between groups. All tests were two-sided with the level of significance set at 0.01 to take account of multiple testing.

\section{Surgical technique}

Surgery was performed under general or regional anaesthesia with use of an arm tourniquet and administration of antibiotics according to local policy. A standard volar approach through the bed of Flexor Carpi Radialis was performed. The Stryker Matrix Smartlock volar locking plate (Stryker Leibinger GmbH \& Co. Germany) was used in all cases. This is a low profile, titanium plate incorporating 20 degree variable angle locking for all screws. Skin closure and postoperative immobilisation was according to the operating surgeon's preference. Bone grafting and carpal tunnel decompression were not routinely performed, although carpal tunnel decompression was done at the time of internal fixation in 10 patients at the discretion of the operating surgeon. Reasons for decompression included pre-existing carpal 
tunnel syndrome $(\mathrm{n}=2)$; pre-operative symptoms of median nerve compression $(\mathrm{n}=5)$ and excessive intraoperative swelling $(n=3)$. Ulna styloid fractures were not treated operatively in any patients. Distal RadioUlnar Joint (DRUJ) instability was documented in only one case and was treated with Kirschner wire stabilisation for six weeks.

\section{Results \& discussion}

The median DASH score for all patients was 2.3 (IQR 06.4) and the median MAYO score was 90 (IQR 75-100). The MAYO and DASH scores were good or excellent in 133 patients (74\%), satisfactory in $41(23 \%)$ and poor in six patients (3\%). There was a strong relationship between the two scoring systems with virtually no variation in outcomes. Figure 1 and 2 show the distribution and frequency of DASH and MAYO scores for the whole group.

\section{Possible variables affecting functional outcome}

132 patients were female (73\%) and 51 were male (27\%). There was little variation in the MAYO score between men and women, however the DASH score for women was more variable than in men. A Mann-Whitney test showed some indication of a higher DASH score in women than in men $(\mathrm{p}=0.025)$, however when taking

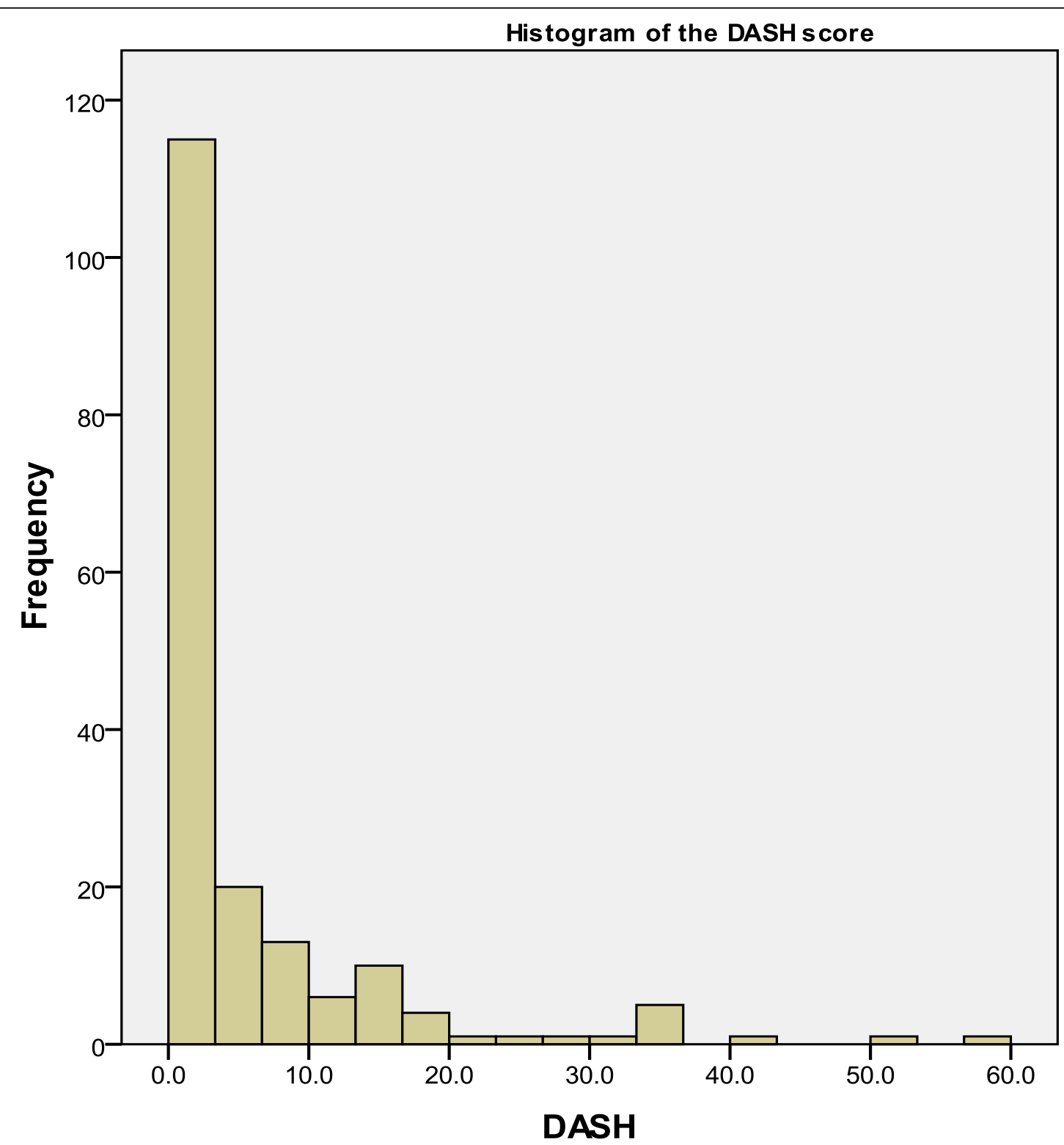

Figure 1 Histogram showing distribution and frequency of DASH scores. 


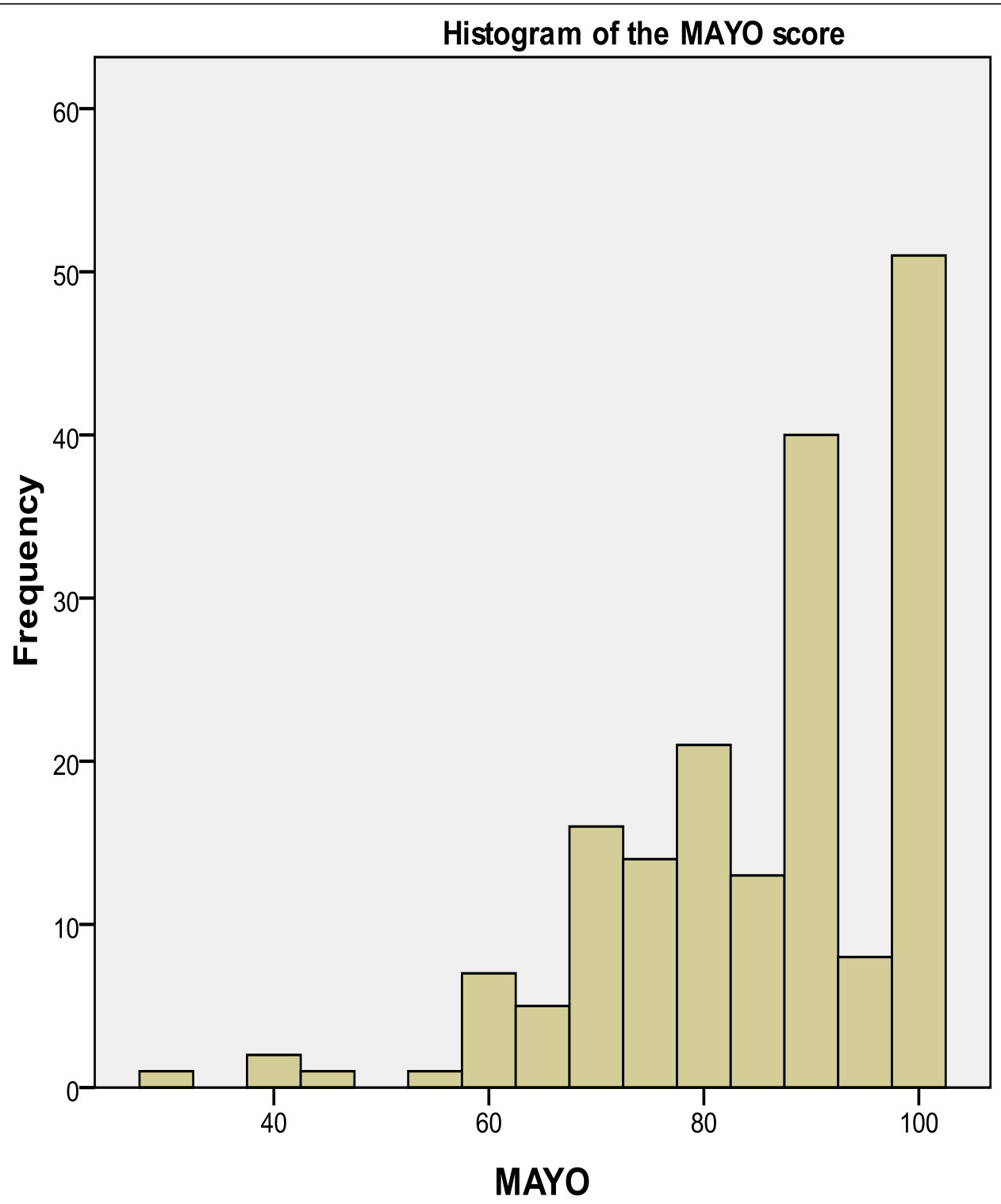

Figure 2 Histogram showing distribution and frequency of MAYO scores

into account multiple testing using the Bonferroni adjustment, this is was not considered statistically significant.

Mean age was 62.4 years (range16-93; SD 17.9). No relationship was seen between age and either the MAYO or DASH score (Spearman's correlation coefficient, MAYO 0.03; DASH 0.04).

Mean time to surgery was 8 days (range $0-28$ days; SD 6.4). No relationship was seen between time to surgery and either the MAYO or DASH score (Spearman's correlation coefficient, MAYO -0.09; DASH 0.1).

Mean time at follow up was 30 months post operatively (13-53 months; SD 10.4). In total, 62 patients (34\%) were followed up in their second postoperative year; $69(38 \%)$ in year three; $42(23 \%)$ in year four and seven $(4 \%)$ in year five. Patients did not have significantly different functional outcome according to their year of follow up.

The primary surgeon was a consultant in 56 cases (31\%) and was a middle grade (trainee registrar or staff grade surgeon) in 127 cases (69\%). In total 26 different surgeons performed all operations. Using the KruskalWallis test there was no evidence of a difference in MAYO ( $p=0.38)$ or DASH score $(\mathrm{p}=0.73)$ for the different surgeon grades.

Post-operative immobilisation for between four and six weeks was instituted in 76 patients $(42 \%)$ as opposed to immediate graduated mobilisation in the remaining 
107 patients (68\%). This was surgeon dependent and there was no significant discrepancy between the two groups in terms of fracture type or patient age. There was no statistical difference between the groups in terms of functional outcome (DASH $\mathrm{p}=0.06$; MAYO $\mathrm{p}$ $=0.11$ ) or in the incidence Chronic Regional Pain Syndrome (CRPS) ( $\mathrm{p}=0.09$ ).

Table 2, shows a breakdown of the differing fracture types. Mean DASH and MAYO scores were comparable for all fracture types and there was no evidence of a difference in MAYO ( $\mathrm{p}=0.90)$ and DASH scores ( $\mathrm{p}=$ $0.80)$ for the different fracture types (Kruskal-Wallis).

\section{Radigraphic analysis}

133 patients (74\%) had post-operative radiographs available for analysis. This was because there was a change over to electronic imaging in the first year of the study period making it difficult to access all radiograph hard copies.

Overall mean time to fracture union was 8.4 weeks (628 weeks). Table 3 , shows time to union by fracture type. Although there was a trend towards increasing union time with higher energy fracture type, this did not prove to be significant (Kruskal-Wallis $\mathrm{p}=0.35$ ). There were no cases of non-union.

\section{Complications}

In total, 27 patients (15\%) suffered a postoperative complication. These are outlined in table 4.11 patients (6\%) sustained a major complication, defined as deep infection, tendon rupture, acute carpal tunnel syndrome and chronic regional pain syndrome. Two patients developed persistent tingling in the median nerve distribution post operatively. Neither of these had a motor deficit or preoperative median nerve dysfunction. Both were expediently taken back to theatre within 12 hours of surgery for carpal tunnel decompression, which resolved their symptoms. Of the three tendon ruptures, two were of
Extensor Pollicis Longus (EPL) and one was of Flexor Pollicis longus (FPL). One EPL rupture had protruding screws dorsally whereas the other did not. The case with the FPL rupture did not have a prominent plate radially however at the time of removal it was found that the radial screw had not been fully locked into the plate, making its prominence the likely cause for rupture. The mean DASH and MAYO scores for patients suffering a postoperative complication were 9.0 and 80.3 respectively. Plate removal was performed in 17 patients (9\%). This was for deep infection in one case; tendon rupture in three cases; prominent dorsal screws in three cases; late carpal tunnel syndrome in two patients and at the patients request in seven cases. There were no further incidences of plate related complications.

\section{Discussion}

We present one of the largest single centre case series of this kind, with good or excellent outcome in the majority of patients at 30 months follow up. While there are long term studies looking at the outcomes of patients treated non-operatively [3,7], with external fixation [15], and percutaneous fixation [16.17], there are few studies documenting the functional outcome after volar plate fixation beyond 2 years post operatively. Rozental et al. showed mostly good and excellent functional outcomes in 45 patients at 17 months mean follow up [18]. Similar larger series $[19,20]$ have reviewed the outcome of volar plate fixation in cohorts of 150 (24 months follow up) and 114 (12 months) patients respectively. Like our study these both showed good to excellent functional outcome using the DASH score. Of note however, there was a $22 \%$ loss to follow up at 24 months in one series [19].

Our study is limited by the fact that it is retrospective. This did not allow us to follow up patients at several time points after surgery and correlate progression in functional score with time. Other authors have

Table 2 Classification of fracture types and corresponding DASH and MAYO scores

\begin{tabular}{|c|c|c|c|c|c|c|c|c|}
\hline $\begin{array}{l}\text { Fracture Type } \\
\text { (AO-ASIF) }\end{array}$ & Frequency & Percentage & $\begin{array}{l}\text { Combined } \\
\text { Frequency }\end{array}$ & $\begin{array}{l}\text { Combined } \\
\text { Percentage }\end{array}$ & $\begin{array}{l}\text { Combined } \\
\text { Mean DASH }\end{array}$ & $\begin{array}{l}\text { Combined } \\
\text { Mean MAYO }\end{array}$ & $\begin{array}{l}\text { Combined } \\
\text { Median DASH }\end{array}$ & $\begin{array}{l}\text { Combined } \\
\text { Median MAYO }\end{array}$ \\
\hline 23-A1 & 0 & $0 \%$ & 94 & $51.4 \%$ & & & & \\
\hline $23-\mathrm{A} 2$ & 34 & $18.6 \%$ & & & 6.5 & 84.0 & 2.3 & 90 \\
\hline $23-A 3$ & 60 & $32.8 \%$ & & & $\mathrm{SD}=11.3$ & $\mathrm{SD}=9.3$ & $\mathrm{IQR}=0-6.8$ & $\mathrm{IQR}=80-100$ \\
\hline 23-B1 & 7 & $3.8 \%$ & 18 & $9.8 \%$ & & & & \\
\hline $23-B 2$ & 1 & $0.5 \%$ & & & 5.4 & 85.4 & 3.4 & 82.5 \\
\hline $23-B 3$ & 10 & $5.5 \%$ & & & $\mathrm{SD}=8.6$ & $S D=13.3$ & $\mathrm{IQR}=0-5.7$ & $\mathrm{IQR}=70-100$ \\
\hline $23-\mathrm{C} 1$ & 12 & $6.6 \%$ & 71 & $38.8 \%$ & & & & \\
\hline $23-C 2$ & 35 & $19.1 \%$ & & & 3.5 & 88.1 & 1.7 & 90 \\
\hline $23-C 3$ & 24 & $13.1 \%$ & & & $\mathrm{SD}=6.5$ & $S D=9.32$ & $I Q R=0-5$ & $I Q R=75-100$ \\
\hline Total & 183 & 100 & 183 & 100 & & & & \\
\hline
\end{tabular}


Table 3 Time to Fracture Union with varying fracture type

\begin{tabular}{lllllll}
\hline $\begin{array}{l}\text { Fracture Type } \\
\text { AO-ASIF }\end{array}$ & Frequency Percentage & $\begin{array}{l}\text { Mean time to union } \\
\text { (weeks) }\end{array}$ & $\begin{array}{l}\text { Standard Deviation } \\
\text { (weeks) }\end{array}$ & $\begin{array}{l}\text { Median time to union } \\
\text { (weeks) }\end{array}$ & $\begin{array}{l}\text { Inter Quartile Range } \\
\text { (weeks) }\end{array}$ \\
\hline $23-\mathrm{A} 2$ & 15 & $11.3 \%$ & 7.4 & 1.6 & 7 & $6-8$ \\
\hline $23-\mathrm{A} 3$ & 50 & $37.6 \%$ & 7.7 & 2.5 & 7 & $6-8$ \\
\hline $23-\mathrm{B}$ & 7 & $5.3 \%$ & 8.29 & 3.6 & 7 & $6-9$ \\
\hline $23-\mathrm{C} 1$ & 8 & $6.0 \%$ & 6.63 & 0.7 & 8 & $6-7$ \\
\hline $23-\mathrm{C} 2$ & 30 & $22.6 \%$ & 8.73 & 3.0 & 8 & $6-10$ \\
\hline $23-\mathrm{C3}$ & 23 & $17.3 \%$ & 10.74 & 7.4 & & $6-17$ \\
\hline Total & 133 & $100 \%$ & & & & \\
\hline
\end{tabular}

demonstrated that improvement in functional scoring is particularly applicable to the first year after surgery $[21,22]$. Goldfarb et al. and Catalano et al. followed up the same cohort of patients at a mean of 7 and 15 years after open reduction and stabilisation with wires and showed a long term progressive increase in functional score $[23,24]$. However, there is no current data to show whether a similar improvement is seen after volar locking plate fixation. The mean DASH scores in our study are better than in the corresponding papers mentioned and we feel this reflects the longer follow up time and infers that functional scores may continue to improve with time.

We used the MAYO wrist score alongside the DASH score to assess functional outcome. There was no discrepancy between the two scoring systems in terms of grading outcome. Although the two scoring systems are not directly comparable, the use of two systems reduces the likelihood of errors generated by the use of a single system. We used the quick DASH score which is comprised of 11 questions and has been shown to have similar cross-sectional and test-retest reliability to the traditional 30 point full DASH score [8-11]. Although not significantly different, Gummesson et al. showed quick DASH scores tended to be higher than DASH scores [10]. This reassures us that the scores we recorded are reliable and comparable to other studies.

We had expected fracture type, surgeon grade, time to surgery or patient age to be possible factors, which affected functional outcome, however we were not able

Table 4 Post-operative complications

\begin{tabular}{llll}
\hline Major Complications & \multicolumn{3}{l}{ Minor Complications } \\
\hline Unresolved CRPS & 5 & Resolved CRPS & 11 \\
\hline Tendon Rupture & 3 & $\begin{array}{l}\text { Late carpal tunnel } \\
\text { syndrome }\end{array}$ & 2 \\
\hline $\begin{array}{l}\text { Acute Carpal Tunnel } \\
\text { Syndrome }\end{array}$ & 2 & Superficial Infection & 2 \\
\hline Deep Infection & 1 & Hypertrophic scar & 2 \\
\hline Total & $\begin{array}{l}\mathbf{1 1} \\
\mathbf{( 6 \% )}\end{array}$ & Total & $\mathbf{1 6}$ \\
\hline
\end{tabular}

to demonstrate this. This is actually consistent with the findings of other studies $[21,22]$. It is likely that the fact that we assessed patients at a single time point long after their original surgery may have allowed any initial discrepancies to even out. We suspect that if we had followed up patients prospectively at multiple time points, factors such as post-operative immobilisation, age and time to surgery would have been more influential on functional outcome. Nevertheless, it is reassuring that in the longer term these factors do not appear detrimental to functional outcome. With regard to surgeon grade and fracture type, the results may be masked by the fact that more senior surgeons tackled the more complex fractures, thus making it difficult to assess the true influence of surgeon grade.

Only one type volar locking plate was used for all patients in this series as this was the only implant available at our centre during the study period. Subsequent development has lead to the design of many newer plates with a variety of features including different locking mechanisms, material properties and fragment specific designs. The use of newer plates may have changed outcomes in some way, however the basic principles of fracture reduction, stable fixation and respect for the soft tissues remain paramount regardless of implant.

Many studies reviewing various methods of fixation look at radiographic parameters that affect outcome, however few if any have looked at surgeon grade or time to surgery as we have. In a large radiographic study, Mackenney et al. showed that age over 80 years; metaphyseal comminution and positive ulna variance were the main predictors of instability. This and poor radio-carpal alignment were shown to be associated with poor outcome [7]. However this study did not look at results after fixation with a volar locking plate, which has specific design applications for use in osteoporotic unstable fracture patterns. We chose not to assess radiographic parameters such as residual intraarticular step, correction of normal distal radial anatomy and presence of post traumatic osteoarthritis as we were interested purely in patient centered outcome and these radiographic features have consistently been 
shown not to correlate with functional outcome [4,21-24].

At the time of the study and currently, it is not our practice to treat Ulna styloid fractures surgically. This is based on the fact that they have not conclusively been shown to alter functional outcome $[2,25,26]$.

The only factor that was associated with a poorer functional outcome was the development of a postoperative complication. The 27 patients with a postoperative complication had both DASH and MAYO scores considerably worse than the other patients, and those with what we classed as a major complication (10 patients) had a much worse functional score. The two patients who acutely developed post operative carpal tunnel syndrome were both females under the age of 60 years. Neither had preoperative symptoms. One had a 23-C2 type fracture whilst the other had a 23-A2 fracture. Ring et al. suggested that younger women with significantly translated fractures may be at higher risk of carpal tunnel syndrome however, other authors have not advocated the need for carpal tunnel decompression as a routine in any fracture type, age group or gender [2,27-30]. Whether to routinely perform carpal tunnel decompression in certain patients remains controversial and it remains our policy to select patients on a caseby-case basis.

16 patients developed features of CRPS at some point in their follow up. In order to avoid under reporting the incidence of CRPS, we included all patients who had any mention of CRPS type symptoms (e.g disproportionate or neurogenic type pain; trophic changes to the skin; persistent swelling) in their follow up records. There was no correlation between fracture type or period of immobilisation and the incidence of CRPS, however, the mean age of those with CRPS was younger (58.9 years) than the group as a whole. Also, 13 (81\%) of these patients were female. This finding is in keeping with other reported incidences of CRPS after distal radius fracture [30]. We now use vitamin $C$ prophylactically for CRPS prevention as recommended by Zollinger et al. [31]

It is not viable to statistically compare the DASH and MAYO scores of those with a complication and the general cohort, as 'complications' are an outcome in themselves, and these patients were not pre-defined for comparison. However, it can be inferred that those who sustain a complication are likely to have a worse functional outcome. Our overall complication rate is comparable or better than other reported treatment modalities including non-operative treatment $[3,17]$, percutaneous fixation $[16,31,32]$, volar locking plate fixation [5,18-21,33-38] and external fixation [15,18,33-35,38]. What is clear is that whilst this treatment modality offers good to excellent long-term results, with a low incidence of complication, when complications do occur, the functional impairment incurred is long lasting and hence surgery must be performed with great care and by well trained operators. On balance, we do not recommend routine removal of plates given that plate related complications in our series were few.

As this is a retrospective non-comparative study, we cannot disregard other treatment modalities for distal radius fracture. However, there is a growing body of evidence that supports volar locking plate fixation as the modality of choice when surgery is indicated. We feel that this study which is the largest of this kind supports this trend but do acknowledge that further high quality trials are necessary to better answer this contentious issue.

\section{Conclusions}

This large series demonstrates good to excellent results in the majority of patients after volar locking plate fixation of the distal radius, with complication rates comparable to other non-operative and operative treatment modalities. Those who suffer a complication have a much worse functional outcome, hence, while we recommend this mode of fixation for distal radius fractures requiring operative intervention, utmost care must be exercised to prevent complications and identify them early.

\section{Author details}

'Orthopaedic Department, Frimley Park Hospital, Camberley, GU16 7UJ, UK. ${ }^{2}$ Orthopaedic Department, Kingston Hospital, Galsworthy Road, KT2 7QB, UK. ${ }^{3}$ Orthopaedic Department, St Peters Hospital, Chertsey, KT16 OPZ, UK.

${ }^{4}$ Medical statistics department, Cambridge University, CB2 1TN, UK.

\section{Authors' contributions}

JP, AT and KG collected the data and compiled the patient database. They followed up the patients and wrote the paper. LB performed all statistical analysis. DSE \& KJN were responsible for the conception of the study and supervision of the project. They proof read and amended the paper as necessary. All authors have read and approved the manuscript.

\section{Competing interests}

The authors declare that they have no competing interests.

Received: 21 June 2011 Accepted: 26 January 2012

Published: 26 January 2012

\section{References}

1. Jupiter JB: Fractures of the distal end of the radius. J Bone Joint Surg Am 1991, 73:461-9.

2. Lichtman DM, Bindra RR, Boyer MI, Putnam MD, Ring D, Distal radius work group: The treatment of distal radius fractures. J Am Acad Orthop Surg 2010, 18:180-189.

3. Handoll HH, Huntley JS, Madhok R: External fixation versus conservative treatment for distal radial fractures in adults. Cochrane Database Syst Rev 2007, 18(3):CD006194.

4. Knirk $J L$, Jupiter JB: Intra-articular fractures of the distal end of the radius in young adults. J Bone Joint Surg Am 1986, 68:647-59.

5. Jupiter JB, Ring D, Weitzel PP: Surgical treatment of re-displaced fractures of the distal radius in patients older than 60 years. J Hand Surg Am 2002, 27:714-23. 
6. Koval KJ, Harrast JJ, Anglen JO, Weinstein JN: Fractures of the distal part of the radius. The evolution of practice over time. Where's the evidence? J Bone Joint Surg Am 2008, 90:1855-61.

7. Mackenney PJ, McQueen MM, Elton R: Prediction of Instability in Distal Radial Fractures. J Bone Joint Surg Am 2006, 88:1944-1951.

8. Beaton D, Wright J, Katz J: Development of the Quick DASH: Comparison of Three Item-Reduction Approaches. J Bone Joint Surg Am 2005, 87:1038-1046.

9. Hudak PL, Amadio PC, Bombardier C: Development of an upper extremity outcome measure: the DASH (disabilities of the arm shoulder and hand). The Upper Extremity Collaborative Group (UECG). Am J Ind Med 1996, 29:602-8

10. Gabel CP, Yelland M, Melloh M, Burkett B: A modified QuickDASH-9 provides a valid outcome instrument for upper limb function. $B M C$ Musculoskelet Disord 2009, 18(10):161.

11. Gummesson C, Ward MM, Atroshi I: The shortened disabilities of the arm, shoulder and hand questionnaire (QuickDASH): validity and reliability based on responses within the full-length DASH. BMC Musculoskelet Disord 2006, 18(7):44

12. Souer JS, Lozano-Calderon SA, Ring D: Predictors of wrist function and health status after operative treatment of fractures of the distal radius. $J$ Hand Surg Am 2008, 33(2):157-163.

13. Marsh J: OTA Fracture Classification. J Orthop Trauma 2009, 23(8):551.

14. Corrales LA, Morshed S, Bhandari M, Miclau T: The Variability in the Assessment of Fracture-Healing in Orthopaedic Trauma Studies. J Bone Joint Surg Am 2008, 90:1862-1868.

15. Hayes AJ, Duffy P, McQueen M: Bridging and non-bridging external fixation in the treatment of unstable fractures of the distal radius: $A$ retrospective study of 588 patients. Acta Orthopaedica 2008, 79(4):540-547.

16. Kreder HJ, Hanel DP, Agel J, McKee M, Schemitsch EH, Trumble TE, Stephen D: Indirect reduction and percutaneous fixation versus open reduction and internal fixation for displaced intra-articular fractures of the distal radius: a randomised, controlled trial. J Bone Joint Surg Br 2005, 87:829-36.

17. McQueen MM, Hajducka C, Court-Brown CM: Redisplaced unstable fractures of the distal radius: a prospective randomised comparison of four methods of treatment. J Bone Joint Surg Br 1996, 78:404-9.

18. Rozental TD, Blazar PE: Functional outcome and complications after volar plating for dorsally displaced, unstable fractures of the distal radius. $J$ Hand Surg Am 2006, 31:359-65.

19. Jupiter JB, Marent-Huber M, LCP Study Group: Operative management of distal radial fractures with 2.4-millimeter locking plates. A multi-center prospective case series. J Bone Joint Surg Am 2009, 91:55-65.

20. Arora R, Lutz M, Hennerbichler A, Krappinger D, Espen D, Gabl M: Complications following internal fixation of unstable distal radius fracture with a palmar locking-plate. J Orthop Trauma 2007, 21(5):316-22.

21. Lozano-Calderon SA, Souer S, Mudgal C, Jupiter JB, Ring D: Wrist Mobilization Following Volar Plate Fixation of Fractures of the Distal Part of the Radius. J Bone Joint Surg Am 2008, 90:1297-1304.

22. Souer SJ, Ring D, Jupiter JB, Matschke S, Audige L: Comparison of AO Type- $B$ and Type- $C$ Volar Shearing Fractures of the Distal Part of the Radius. J Bone Joint Surg Am 2009, 91:2605-2611.

23. Goldfarb CA, Rudzki JR, Catalano LW, Hughes M, Borrelli J: Fifteen-year outcome of displaced intra-articular fractures of the distal radius. J Hand Surg Am 2006, 31:633-9.

24. Catalano LW, Cole RJ, Gelberman RH, Evanoff BA, Gilula LA, Borrelli J: Displaced intra-articular fractures of the distal aspect of the radius. Long-term results in young adults after open reduction and internal fixation. J Bone Joint Surg Am 1997, 79:1290-302.

25. $\mathrm{Ng} \mathrm{CY,} \mathrm{McQueen} \mathrm{MM:} \mathrm{What} \mathrm{are} \mathrm{the} \mathrm{radiological} \mathrm{predictors} \mathrm{of} \mathrm{functional}$ outcome following fractures of the distal radius? J Bone Joint Surg Br 2011, 93-B:145-150.

26. Zenke Y, Sakai A, Oshige T, Moritani S, Nakamura T: The effect of an associated ulnar styloid fracture on the outcome after fixation of a fracture of the distal radius. J Bone Joint Surg Br 2009, 91-B:102-107.

27. Dyer G, Lozano-Calderon S, Gannon C, Baratz M, Ring D: Predictors of acute carpal tunnel syndrome associated with fracture of the distal radius. J Hand Surg Am 2008, 33(8):1309-1313.
28. Odumala O, Ayekoloye C, Packer G: Prophylactic carpal tunnel decompression during buttress plating of the distal radius-is it justified? Injury 2001, 32(7):577-579.

29. Fuller DA, Barrett M, Marburger RK, Hirsch R: Carpal canal pressures after volar plating of distal radius fractures. J Hand Surg Br 2006, 31(2):236-239.

30. Berglund L, Messer T: Complications of Volar Plate Fixation for Managing Distal Radius Fractures. J Am Acad Orthop Surg 2009, 17:369-377.

31. Zollinger E, Tuinebreijer WE, Breederveld RS, Kreis RW: Can Vitamin C Prevent Complex Regional Pain Syndrome in Patients with Wrist Fractures? A Randomized, Controlled, Multicenter Dose-Response Study. J Bone Joint Surg Am 2007, 89:1424-1431.

32. Glickel SZ, Catalano LW, Raia FJ, Barron OA, Grabow R, Chia B: Long-term outcomes of closed reduction and percutaneous pinning for the treatment of distal radius fractures. J Hand Surg Am 2008, 33(10):1700-5.

33. Wright TW, Horodyski M, Smith DW: Functional outcome of unstable distal radius fractures: ORIF with a volar fixed-angle tine plate versus external fixation. J Hand Surg Am 2005, 30:289-299.

34. Egol K, Walsh M, Tejwani N, Mclaurin T, Wynn C, Paksima N: Bridging external fixation and supplementary Kirschner-wire fixation versus volar locked plating for unstable fractures of the distal radius. J Bone Joint Surg Br 2008, 90(9):1214-1221.

35. Wei DH, Raizman NM, Bottino CJ, Jobin CM, Rosenwasser MP: Unstable distal radial fractures treated with, external fixation, a radial column plate or a volar plate. A prospective randomized control trial. J Bone Joint Surg Am 2009, 91:1568-1577.

36. Leung F, Zhu L, Ho H, Lu WW, Chow SP: Palmar plate fixation of AO type C2 fracture of distal radius using a locking compression plate-a biomechanical study in a cadaveric model. J Hand Surg Br 2003, 28:263-6.

37. Orbay JL, Fernandez DL: Volar fixed-angle plate fixation for unstable distal radius fractures in the elderly patient. J Hand Surg Am 2004 29:96-102.

38. Leung F, Tu YK, Chew WY, Chow SP: Comparison of external and percutaneous pin fixation with plate fixation for intra-articular distal radial fractures. A randomized study. J Bone Joint Surg Am 2008, 90:16-2.

doi:10.1186/1749-799X-7-4

Cite this article as: Phadnis et al.: Mid-term functional outcome after the internal fixation of distal radius fractures. Journal of Orthopaedic Surgery and Research 2012 7:4.

\section{Submit your next manuscript to BioMed Central and take full advantage of:}

- Convenient online submission

- Thorough peer review

- No space constraints or color figure charges

- Immediate publication on acceptance

- Inclusion in PubMed, CAS, Scopus and Google Scholar

- Research which is freely available for redistribution

Submit your manuscript at www.biomedcentral.com/submit
C Biomed Central 